\title{
INTERNALISASI IDEOLOGI PANCASILA MELALUI LAGU KEBANGSAAN UNTUK MENCEGAH MEMUDARNYA NASIONALISME
}

\author{
Uswatun Hasanah ${ }^{1}$ \\ ${ }^{1}$ Universitas Pancamarga Probolinggo \\ Email: usanah89@gmail.com
}

Received: Nov 2, 2020 Revised: Nov 10, 2020 Accepted: Nov 12, 2020

\begin{abstract}
ABSTRAK
Perkembangan zaman yang semakin maju berdampak positif dan negatif untuk bangsa kita. Salah satu dampak negatifnya adalah memudarnya rasa nasionalisme generasi penerus bangsa. Untuk mencegah atau meminimalisir memudarnya rasa nasionalisme bangsa kita mulai dari hal kecil yaitu melalui lagu kebangsaan. Pada kenyataannya musik atau lagu selalu menyertai dalam segala aktivitas kita, karena dengan mendengarkan musik atau lagu dapat menjadikan perasaan lebih senang. Akan tetapi realitanya generasi muda sekarang lebih suka lagu luar negeri daripada lagu kebangsaan. Hal ini salah satu contoh memudarnya rasa nasionalisme generasi muda kita. Tujuan dari internalisasi ideologi Pancasila melalui lagu kebangsaan adalah melalui lagu diharapkan dapat mempengaruhi perilaku dan sikap generasi muda untuk menanamkan nilai-nilai Pancasila. Dengan menanamkan nilai Pancasila diharapkan dapat membenahi moral generasi untuk mencegah memudarnya rasa nasionalisme. Nasionalisme sangat penting untuk keutuhan Negara Kesatuan Republik Indonesia. Pancasila merupakan ideologi bangsa dan merupakan jati diri bangsa Indonesia. Dalam pelaksanaan internalisasi ideologi Pancasila ada beberapa tahapan yaitu penanaman nilai Pancasila, penumbuhan jiwa Pancasila, pengembngan nilai Pancasila, dan pemantapan jiwa Pancasila pada generasi muda. Agar dapat terealisasi semua itu peran dari pendidikan, keluarga dan pemerintah sangat penting mengingat pentingnya nilai Pancasila untuk diimplementasikan dalam kehidupan sehari-hari dalam bermasyarakat dan memperkuat nasionalisme dan patriotisme generasi penerus bangsa.
\end{abstract}

Kata Kunci: Pancasila, lagu kebangsaan, nasionalisme

\begin{abstract}
The times that are increasingly advanced have positive and negative impacts on our nation. One of the negative impacts is the waning sense of nationalism for the
\end{abstract}


next generation of the nation. To prevent or minimize the fading of our nation's sense of nationalism, start from small things, namely through the national anthem. In fact, music or songs always accompany our activities, because listening to music or songs can make us feel happier. However, in reality the younger generation now prefers foreign songs to the national anthem. This is an example of the waning sense of nationalism in our youth. The purpose of internalizing the Pancasila ideology through the national anthem is through songs which are expected to influence the behavior and attitudes of the younger generation to instill Pancasila values. By instilling the values of Pancasila, it is hoped that it can improve the morale of the generation to prevent the waning sense of nationalism. Nationalism is very important for the integrity of the Republic of Indonesia. Pancasila is the nation's ideology and is the identity of the Indonesian nation. In the implementation of the internalization of the Pancasila ideology, there are several stages, namely planting the values of Pancasila, developing the spirit of Pancasila, developing the values of Pancasila, and strengthening the spirit of Pancasila in the younger generation. In order to realize all of these the roles of education, family and government are very important considering the importance of the value of Pancasila to be implemented in everyday life in society and strengthen nationalism and patriotism for the next generation of the nation.

Keywords: Pancasila, national anthem, nationalism

\section{PENDAHULUAN}

Para pendiri republik ini dengan penuh ketulusan merumuskan dan menggali nilai-nilai filosofis bangsa, di tengah-tengah perjuangan melawan imperealisme. Kiranya para tokoh pendiri Negara Indonesia menyadari, realitas objektif yang ada pada bangsa Indonesia sebagai kausa materialis (Kaelan, 2013). Kausa Materialis adalah Pancasila yang sekarang menjadi ideologi negara bersumber pada bangsa Indonesia, artinya bangsa Indonesia sebagai Kausa Materialis. Pancasila merupakan dasar negara republik Indonesia. Maka Kuntowijoyo, 2001 berpendapat bahwa penting menekankan radikalisasi Pancasila dalam negara Indonesia yaitu bagaimana meletakkan Pancasila secara radikal dan efektif sebagai pedoman bagi kehidupan dalam berbangsa dan bernegara.

Pancasila sebagai dasar negara republik Indonesia maka diharapkan warga negara mempunyai jiwa Pancasila. Oleh karena itu tidaklah mengherankan jikalau Soekarno menegaskan bahwa nilai-nilai Pancasila merupakan suatu weltanchauung bangsa Indonesia (Kaelan, 2013). Weltanscahuung dari istilah Jerman ini sepadan dengan dengan istilah Inggris: world-view; world look; pandangan dunia. Weltanscahuung adalah pandangan tentang dunia, pengertian tentang realitas, sebagai suatu keseluruhan. Pandangan umum tentang dunia ini berarti pandangan yang menyangkut soal hakikat, nilai, arti, tujuan dunia, dan hidup manusia dan dapat dikatakan Weltanscahuung merupakan sistem prinsip- 
prinsip, pandangan-pandangan, dan keyakinan-keyakinan dapat menentukan kegiatan arah individu, kelompok sosial, klas, atau masyarakat (Lorens Bagus, 2000).

Sungguh besar jasa para pejuang kita tetapi zaman sekarang berbanding terbalik dengan zaman dahulu. Suatu negara bisa maju tergantung dari warga negaranya, tapi pada kenyataannya sekarang generasi penerus bangsa sangat memprihatinkan. Banyak terjadi tawuran yang dilakukan oleh pelajar, terjerat narkoba, dan masih banyak yang lain. Kenakalan remaja tersebut merupakan salah satu tanda rasa nasionalisme telah memudar. Ini adalah tugas bagi kita semua untuk menanamkan rasa nasionalisme dan patriotisme kepada anak dan cucu kita, peran pemerintah dan keluarga sangat dibutuhkan untuk menanamkan nilai-nilai Pancasila, dimana Pancasila sebagai pandangan hidup bagi warga negara dapat menjadi kontrol untuk mengambil keputusan dan melakukan sebuah tindakan dalam suatu kehidupan sosial karena manusia merupakan makhluk sosial tidak dapat hidup sendiri, membutuhkan bantuan orang lain. Nasionalisme sangat penting bagi keutuhan Negara Kesatuan Republik Indonesia, demi mewujudkan cita-cita bersama, mensejahterakan bangsa sesuai dengan pembukaan UndangUndang 1945 maka nasionalisme dan patriotisme harus tetap eksis agar tidak terkikis oleh berjalannya waktu.

\section{PEMBAHASAN}

A. Nasionalisme

Nasionalisme adalah suatu ungkapan perasaan yang kuat dan merupakan usaha pembelaan daerah atau bangsa melawan penguasa luar. Identitas yang menjadi ciri khasnya adalah identitas masa lalu, suatu sejarah, nenek moyang, akar yang menempatkan diri dalam suatu tradisi (sebagai suatu proses peleburan, perpaduan) dari suatu daerah, sejarah, bahasa dan agama (Lyman Tower Sargent, 1987:19). Ada pula pendapat dari para ahli yang lain, yaitu menyatakan bahwa nasionalisme adalah suatu paham yang berpedapat bahwa kesetiaan tertinggi individu harus diserahkan kepada negara kebangsaan. Kebangsaan adalah cita-cita dan satu-satunya bentuk sah dari organisasi politik dan bahwa bangsa adalah sumber semua tenaga kebudayaan kreatif dan kesejahteraan ekonomi (Hans Kohn, 1976:12)

Boyd Shafer (1955: 6) mengatakan bahwa nasionalisme itu multi makna, hal tersebut tergantung pada kondisi objektif dan subjektif dari setiap bangsa. Oleh sebab itu nasionalisme dapat bermakna sebagai berikut: (1) Nasionalisme adalah rasa cinta pada tanah air, ras, bahasa atau budaya yang sama, maka dalam hal ini nasionalisme sama dengan patriotisme. (2) Nasionalisme adalah suatu keinginan akan kemerdekaan politik, keselamatan dan prestise bangsa. (3) Nasionalisme adalah suatu kebaktian mistis terhadap organisme sosial yang kabur, 
kadang-kadang bahkan adikodrati yang disebut sebagai bangsa atau Volk yang kesatuannya lebih unggul daripada bagian-bagiannya. (4) Nasionalisme adalah dogma yang mengajarkan bahwa individu hanya hidup untuk bangsa dan bangsa demi bangsa itu sendiri. (5) Nasionalisme adalah doktrin yang menyatakan bahwa bangsanya sendiri harus dominan atau tertinggi di antara bangsa-bangsa lain dan harus bertindak agresif.

Uraian diatas merupakan pendapat beberapa ahli mendeskripsikan tentang nasionalisme. Rasa nasionalisme ada beberapa aspek yang harus dipahami, seperti yang dinyatakan oleh seorang ahli Apter, 1967: 97 menyatakan bahwa nasionalisme dalam kerangka ideologi maka di dalamnya terkandung aspek: (1) cognitive; (2) goal/value orientation; (3) stategic. Aspek cognitive mengandaikan perlunya pengetahuan atau pemahaman akan situasi konkret sosial, ekonomi, politik dan budaya bangsanya. Maka peran aktif kaum intelektual dalam pembentukan semangat nasional amatlah penting, sebab mereka lah yang memberikan pengetahuan kepada generasi muda bahwa nasionalisme sangat penting untuk mewujudkan cita-cita bersama. Soedjatmoko juga sependapat dengan hal tersebut, beliau menyatakan bahwa menyebut nasionalisme tidak bisa tidak adalah nasionalisme yang cerdas karena nasionalisme itu harus disinari oleh kebijaksanaan, pengertian, pengetahuan dan kesadaran sejarah (Soedjatmoko, 1991: 29-30) . Aspek goal menunjuk akan adanya cita-cita, tujuan ataupun harapan ideal bersama di masa datang yang ingin diwujudkan atau diperjuangkan di dalam masyarakat dan negara. Cita-cita itu mencakup seluruh aspek kehidupan manusia dalam bidang sosial, ekonomi, politik, budaya, dll. Aspek strategic menuntut adanya kiat perjuangan kaum nasionalis dalam perjuangan mereka untuk mewujudkan cita-cita bersama, dapat berupa perjuangan fisik atau diplomasi, moril atau spirituil tergantung pada situasi, kondisi konkret dan waktu setempat yang dihadapi oleh suatu bangsa. Pada masa revolusi bangsa Indonesia berjuang melawan penjajah, tetapi setelah merdeka nasionalisme berjuang melawan kemiskinan, kebodohan dan menegakkan hukum secara adil untuk meraih cita-cita bersama yaitu mensejahterakan bangsa.

Berdasarkan perspektif Sartono Kartodirdjo (1999: 13) menyatakan bahwa masyarakat Indonesia pasca-revolusi dan pasca-reformasi masih menuntut nasionalisme sebagai faktor pemicu dalam proses konsolidasi orde sosial-politik yang dibingkai oleh negara bangsa, terutama jika nasionalisme itu benar-benar disertai dengan kelima prinsip utamanya, yakni menjamin kesatuan (unity) dan persatuan bangsa, menjamin kebebasan (liberty) individu ataupun kelompok, menjamin adanya kesamaan (equality) bagi setiap individu, menjamin terwujudnya kepribadian (personality), dan prestasi (performance) atau keunggulan bagi masa depan bangsa. Selama kelima pilar nasionalisme tersebut masih ada maka nasionalisme akan tetap relevan dan terus dibutuhkan oleh setiap 
bangsa, dan nasionalisme akan terus berkembang, dinamis sesuai dengan tuntutan zaman serta kebutuhan bangsa yang bersangkutan. Oleh sebab itu nasionalisme dari waktu ke waktu dapat berubah dan berkembang dengan tidak melupakan identitas bangsa.

Pada masa modern ini realitanya semakin berkurang rasa nasionalisme generasi penerus kita. Salah satu faktanya adalah banyak terjadi tawuran antara remaja. Hal ini merupakan salah satu contoh memudarnya rasa nasionalisme dimana generasi muda sekarang kurang mempunyai sikap atau perasaan yang kuat untuk meraih cita-cita memajukan bangsa dan negara. Generasi muda kita lupa bahwa kita satu bangsa yaitu bangsa Indonesia. Ada istilah yang menyebutkan bahwa bersatu kita teguh bercerai kita runtuh. Demi mewujudkan cita-cita bangsa kita harus bersatu. Hal serupa pernah dikemukakan oleh Benedict Anderson, beliau berpendapat bahwa pentingnya nasionalisme bagi bangsa Indonesia. Salah satu yang mendesak di Indonesia dewasa ini adalah adanya yang disebut sebagai "defisit nasionalisme", yakni semakin berkurangnya semangat nasional, lebihlebih di kalangan mereka yang kaya dan berpendidikan (Anderson, 2001: 215) . Untuk itu Anderson berpendapat bahwa penting ditumbuhkan kembali semangat nasionalisme seperti para pejuang di masa reformasi dan revolusi.

B. Ideologi Pancasila

Dasar-dasar pembentukan nasionalisme modern dirintis oleh para pejuang kebangkitan nasional pada tahun 1908, kemudian dicetuskan pada sumpah pemuda pada tahun 1928. Akhirnya titik kulminasi sejarah perjuangan bangsa Indonesia dalam mendirikan negara tercapai dengan diproklamasikannya kemerdekaan Indonesia pada tanggal 17 agustus 1945. Berdasarkan fakta sejarah bangsa Indonesia, maka proses perumusan dasar filsafat negara, dibuat dari unsurunsur bangsa Indonesia sendiri. Dasar filsafat negara yaitu Pancasila (Kaelan, 2013). Pancasila sebagai pandangan hidup diharapkan dapat diterapkan dalam kehidupan sehari-hari untuk bersosialisasi dengan masyarakat yang lain karena realitanya manusia adalah makhluk sosial yang tidak dapat hidup sendiri pasti memerlukan bantuan orang lain, dengan mempunyai jiwa Pancasila menjadikan warga negara yang baik dimana setiap individu mempunyai akhlak atau moral yang baik. Jasmani dan rohani yang baik maka setiap perkataan dan perbuatan akan selalu menghormati, menghargai dan mementingkan kepentingan bersama diatas kepentingan pribadi.

Bagi bangsa dan negara Indonesia, dasar filsafat dalam kehidupan bersama itu adalah pancasila. Nilai-nilai dasar yang terkandung dalam filsafat negara tersebut sebagai dasar filosofis-ideologis untuk mewujudkan cita-cita negara, baik dalam arti tujuan prinsip konstitusionalisme sebagai suatu negara hukum formal, maupun empat cita-cita kenegaraan yang terkandung dalam Pembukaan UUD 1945, yaitu: (1) melindungi segenap bangsa dan seluruh tumpah 
darah Indonesia, (2) memajukan (meningkatkan) kesejahteraan umum, (3) mencerdaskan kehidupan bangsa, dan (4) ikut melaksanakan ketertiban dunia berdasarkan perdamaian abadi dan keadilan sosial (Kaelan, 2013).

Nilai-nilai dalam Pancasila diharapkan dapat menjadi sumber nilai atau pandangan hidup seseorang agar menjadi warga negara yang baik dalam berkehidupan sosial. Dengan demikian dalam negara Pancasila pandangan hidup masyarakat tercermin dalam kehidupan negara yaitu pemerintah terikat oleh kewajiban konstitusional, yaitu kewajiban pemerintah dan lain-lain penyelenggara negara untuk memelihara budi perkerti kemanusiaan yang luhur dan memegang teguh cita-cita moral rakyat yang luhur (Darmodiharjo, 1996:35). Berdasarkan perspektif Koentowijoyo menekankan pentingnya radikalisasi Pancasila dalam negara Indonesia yaitu bagaimana meletakkan Pancasila secara radikal dan efektif sebagai pedoman bagi kehidupan dalam berbangsa dan bernegara (Kuntowijoyo, 2001). Dari pernyataan tersebut maka wawasan tentang ideologi Pancasila kepada generasi muda sangat penting karena Pancasila merupakan identitas bangsa Indonesia.

Secara perspektif Poespowardojo (1992), menyatakan bahwa ideologi memiliki fungsi: (a) struktur kognitif ialah keseluruhan pengetahuan yang dapat merupakan landasan untuk memahami dan menafsirkan dunia dan kejadiankejadian alam sekitarnya, (b) orientasi dasar dengan membuka wawasan yang memberikan makna serta menunjukkan tujuan dalam kehidupan manusia, (c) norma yang menjadi pedoman dan pegangan bagi seseorang untuk melangkah dan bertindak, (d) bekal dan jalan bagi seseorang untuk menentukan identitasnya, (e) kekuatan yang mampu menyemangati dan mendorong seseorang untuk menjalankan kegiatan dan mencapai tujuan, (f) pendidikan bagi orang atau masyarakat untuk memahami, menghayati serta mempolakan tingkah lakunya sesuai dengan orientasi dan norma-norma yang terkandung di dalamnya.

Dari pernyataan diatas menyatakan bahwa internalisasi ideologi Pancasila sangat penting bagi generasi muda bangsa Indonesia. Berdasarkan perspektif Kaelan, 2013 menyatakan bahwa pada dasarnya ada dua bentuk realisasinya yaitu bersifat statis (nilai-nilai yang bersifat rokhaniah dan universal bersifat tetap dan tidak berubah) dan bersifat dinamis (aktualisasinya senantiasa bersifat dinamis inovatif, sesuai dengan dinamika masyarakat, perubahan, serta konteks lingkungannya). Proses internalisasi harus diikuti dengan strategi dan metode yang relevan dan memadai. Hal ini berdasarkan realitas objektif, bahwa subjek dan objek internalisasi dan aktualiasi itu adalah manusia dan dalam lingkungan masyarakat, bangsa dan negara. Oleh karena itu dalam proses internalisasi harus diterapkan strategi yang relevan dan metode yang efektif. Internalisasi tidak hanya dalam suatu situasi pendidikan formal saja, melainkan lingkungan pendidikan informal, nonformal, maupun lingkungan masyarakat yang 
lain (Kaelan,2013). Dari pernyataan tersebut maka salah satu cara melakukan internalisasi ideologi Pancasila bisa melalui lagu kebangsaan. Suparlan, 2014 menyatakan bahwa untuk membina rasa nasionalisme dalam Negara Kesatuan Republik Indonesia salah satu nya dengan menghormati dan menghayati isi dan makna lagu kebangsaan. Melalui lagu, diharapkan dapat memberikan wawasan tentang ideologi Pancasila, diharapkan generasi muda mengerti makna dari lagu tersebut dan menghayati dari isi lagu tersebut.

C. Pengaruh Lagu Terhadap Kepribadian

Sejarah penggunaan musik sebagai media penenang psikologi manusia telah dirintis sejak masa filosof Yunani kuno, Plato dan Aristoteles. Orang mendengarkan musik dalam kehidupan sehari-hari karena musik dapat memberikan perasaan yang baik (feeling bette). Menurut beberapa penelitian, menyatakan bahwa perasaan lebih baik ini dapat muncul karena relasi musik dengan emosi, yaitu musik dapat membuat orang merasakan senang, sedih, serta dapat memberikan ketenangan (Sloboda, O’Neill, 2001). Hal yang serupa dinyatakan oleh Justin London (2002) bahwa orang mendengarkan musik karena musik menimbulkan emosi. Emosi yang membuat individu merasakan perasaan yang positif atau perasaan yang lebih baik. Musik, sesuai dengan susunan interval dan ritmenya memiliki refleksi khusus yang bisa merangsang sel-sel saraf sehingga perasaan manusia bisa diperlemah, diperkuat ataupun dialihkan. Pengaruh itu bahkan telah dibuktikan secara ilmiah di sepanjang fase kehidupan manusia, mulai dari masa di embrio hingga masa senja. Penelitian menunjukkan bahwa musik dapat memberikan rangsangan-rangsangan yang kaya untuk segala aspek perkembangan secara kognitif dan kecerdasan emosional (emotional intelligent). Roger Sperry (1992) dalam Siegel (1999) penemu teori Neuron mengatakan bahwa neuron baru akan menjadi sirkuit jika ada rangsangan musik sehingga neuron yang terpisah-pisah itu bertautan dan mengintegrasikan diri dalam sirkuit otak, sehingga terjadi perpautan antara neuron otak kanan dan otak kiri itu.

Jenis musik beat sangat diminati kalangan muda. Jika dimanfaatkan secara tepat, jenis musik ini bisa berdampak positif dan meningkatkan semangat. Musik seperti ini bisa meningkatkan gairah hidup dan memunculkan perasaan positif. Jenis musik ini juga sangat bermanfaat untuk membangkitkan semangat dan keceriaan di kalangan anak-anak ataupun remaja. Dari berbagai penelitian yang telah dilakukan, dunia kedokteran serta psikologi membuktikan bahwa musik bisa dijadikan terapi dan berpengaruh dalam mengembangkan imajinasi dan pikiran kreatif. Berdasarkan perspektif Grace Sudargo, seorang musisi dan pendidik mengatakan bahwa dasar-dasar musik klasik secara umum berasal dari ritme denyut nadi manusia sehingga ia berperan besar dalam perkembangan otak, pembentukan jiwa, karakter, bahkan raga manusia. 
Menurut Siegel (1999) ahli perkembangan otak, mengatakan bahwa musik dapat berperan dalam proses pematangan hemisfer kanan otak, walaupun dapat berpengaruh ke hemisfer sebelah kiri, oleh karena adanya cross-over dari kanan ke kiri dan sebaliknya yang sangat kompleks dari jaras-jaras neuronal di otak. Artinya, hemisfer ini memainkan peran besar dalam proses perkembangan emosi, yang sangat penting bagi perkembangan sifat-sifat manusia yang manusiawi. Hal serupa dinyatakan oleh O'Sullivan (1991) mengemukakan bahwa musik mempengaruhi imaginasi, intelegensi dan memori. Daryono Sutoyo, Guru Besar Biologi UNS Solo, melakukan penelitian (1981) tentang kontribusi musik yaitu menstimulasi otak, mengatakan bahwa pendidikan musik penting diajarkan mulai dari tingkat Sekolah Dasar (SD) agar peserta didik sejak dini memperoleh stimulasi yang seimbang antara belahan otak kiri dan belahan otak kanannya. Bila mereka mampu menggunakan fungsi kedua belahan otaknya secara seimbang, maka apabila mereka dewasa akan menjadi manusia yang berpikir logis dan intutif, sekaligus cerdas, kreatif, jujur, dan tajam perasaannya.

Menurut Albert fungsi kognitif sebagai wakil nilai-nilai kemanusiaan, penentu tingkah laku, teori kognitif-sosial mempelajari ekspektasi, kontrol penguatan diri, kecemasan dan pertahanan dan variabel yang terlibat dengan belajar melalui pengamatan. Jadi tingkat kognitif atau intelektual seorang individu berpengaruh pada tingkah laku seseorang. Pendapat ahli lain juga mengemukakan hal yang sama, tingkah laku dapat dikontrol, ilmu dapat melakukan antisipasi dan membentuk/menentukan tingkah laku seseorang. Jadi tingkat pengetahuan seorang berpengaruh dalam tingkah laku, individu tersebut berpikir dahulu sebelum bertindak.

Musik tidak bisa dipisahkan dari kehidupan kita, bahkan bayi di dalam kandungan seorang ibu dianjurkan untuk diperdengarkan musik untuk merangsang saraf bayi di dalam kandungan. Mulai kecil sampai dewasa kita semua menyukai musik, untuk mengisi kejenuhan pasti mendengarkan musik. Dari penjelasan di atas membahas tentang bagaimana musik atau lagu mempengaruhi kepribadian seseorang. Proses internalisasi harus diikuti dengan strategi dan metode yang relevan dan memadai. Semuanya berdasarkan realitas objektif, bahwa subjek dan objek internalisasi dan aktualiasi itu adalah manusia dan dalam lingkungan masyarakat, bangsa dan negara. Oleh karena itu dalam proses internalisasi harus diterapkan strategi yang relevan dan metode yang efektif. Internalisasi tidak hanya dalam suatu situasi pendidikan formal saja, melainkan lingkungan pendidikan informal, nonformal, maupun lingkungan masyarakat (Kaelan, 2013). Mengingat bahwa musik atau lagu sangat berpengaruh dalam proses perkembangan otak dan mempengaruhi perilaku seorang individu, maka untuk melakukan internalisasi ideologi Pancasila dapat melalui lagu kebangsaan. 
Proses internalisasi ideologi Pancasila meliputi beberapa tahap yaitu (1) Tahap Penanaman. Dalam tahap ini generasi kita diberi pengetahuan tentang sejarah perjuangan proklamasi, semangat berjuang para pejuang kita untuk mengusir penjajah demi kemerdekaan rakyat Indonesia, mengorbankan jiwa dan raga untuk negara tercinta yaitu negara Indonesia, berjuang bersama walau berbeda suku mereka tetap bersatu untuk meraih cita-cita bersama, menanamkan jiwa Pancasila sebagai pedoman hidup dalam berbangsa dan bernegara. (2) Tahap Penumbuhan, yaitu memberikan semangat kebangsaan, menumbuhkan rasa cinta tanah air, mengajarkan bagaimana menjadi warga negara yang baik, mengajarkan akhlak yang baik untuk selalu mengingatkan keberadaan Tuhan Yang Maha Esa, hal tersebut diharapkan menjadi kontrol untuk manusia menjadi kepribadian yang baik, menumbuhkan rasa mengasihi dan saling menghormati dimana manusia adalah makhluk sosial tidak dapat hidup sendiri, membantu orang yang membutuhkan bantuan, dan menghormati perbedaan yang ada di lingkungan sosial karena bangsa Indonesia terdiri dari beberapa suku bangsa (3) Tahap Pengembangan, dalam hal ini seorang individu diberikan stimulasi, apa saja yang harus dilakukan seseorang untuk menjaga keutuhan Negara Kesatuan Republik Indonesia? Merealisasikan Pancasila dalam kehidupan sehari-hari baik dalam bidang kenegaraan maupun dalam bidang kemasyarakatan (4) Tahap Pemantapan, setelah mempelajari beberapa tahap, tahap ini merupakan tahap yang optimal memiliki jiwa Pancasila. Setelah melewati beberapa tahap maka seorang individu bisa menganalisis semua pengetahuan yang mereka ketahui tentang kebangsaan, betapa pentingnya rasa nasionalisme dan penting mempunyai jiwa Pancasila, selain Pancasila merupakan dasar negara, Pancasila bisa menjadi pedoman hidup dalam berbangsa dan bernegara.

Berdasarkan perspektif Notonagoro, (1976: 72,73) menyatakan bahwa meningkatkan semangat dan keteguhan hati yang demikian itu menjadi keyakinan Pnacasila, yaitu keyakinan akan kebenaran Pancasila kemudian meningkatkan menjadi keteguhan keyakinan terhadap Pancasila. Akhirnya menjadi suatu ketahanan ideologis. Suatu ketahanan ideologis merupakan suatu syarat mutlak bagi tercapainya tujuan cita-cita nasional dan yang terpenting mampu menangkal pengaruh ideologi maupun gerakan intervensi ideologi dari negara asing.

Diharapkan keluarga juga mengajarkan tentang semangat cinta tanah air dan menanamkan jiwa Pancasila sejak dini, usia anak-anak adalah usia terbaik untuk menyerap informasi, dengan belajar Pancasila sejak kecil maka seorang individu mempunyai kebiasaan tersebut sampai dia dewasa kelak. Sangat penting menanamkan jiwa Pancasila, selain merupakan identitas bangsa Indonesia Pancasila juga merupakan pedoman hidup dalam berbangsa dan bernegara untuk menciptakan keutuhan Negara Kesatuan Republik Indonesia demi meraih cita-cita bersama. 


\section{KESIMPULAN}

Sudah menjadi tanggung jawab kita untuk membenahi sikap dan moral generasi muda kita. Seperti yang kita ketahui faktor-faktor yang mempengaruhi proses belajar ada dua yaitu faktor dari dalam dan faktor dari luar manusia. Jadi untuk tercapainya proses belajar yang baik peran dari pemerintah, pendidikan dan yang paling penting adalah peran keluarga dapat turut andil untuk menjadikan generasi muda yang bermoral dan mempunyai sikap nasionalisme yang berguna bagi bangsa dan negara.

Usia remaja merupakan usia produktif dimana mereka mempunyai energi yang banyak dan sifat mereka masih labil, maka kita harus menuntun mereka untuk dapat menyalurkan energi mereka untuk hal yang positif yang dapat berguna bagi orang lain dan bagi negara kita. Kita harus membimbing mereka agar hidup mereka lebih bermakna. Menanamkan rasa patriotisme juga sangat penting, karena patriotisme yang dianut bangsa Indonesia adalah wujud kesetiaan terhadap bangsa dan Negara. Patriotisme yang sesungguhnya adalah rela mengorbankan tenaga, harta benda, dan yang lainnya demi bangsa Indonesia. Dengan sikap patriotisme tersebut, maka diharapkan bangsa Indonesia dapat menjadi negara yang kuat dan tidak mudah untuk dijajah.

Kita negara yang unik banyak budaya dan tradisi yang dimiliki oleh bangsa Indonesia. Sungguh indah bangsa kita jika beberapa perbedaan suku dan tradisi bisa hidup bersama dalam satu negara, dimana dalam tradisi kita selalu diajarkan hal-hal yang positif dalam berkehidupan di masayarakat. Sebagai penerus bangsa yang baik kita harus melestarikannya. Dimana nilai-nilai Pancasila merupakan pedoman hidup. Nasionalisme sangat penting terhadap kehidupan berbangsa dan bernegara karena merupakan wujud kecintaan dan kehormatan terhadap bangsa sendiri. Dengan hal itu, pemuda dapat melakukan sesuatu yang terbaik bagi bangsanya, menjaga keutuhan persatuan bangsa, dan meningkatkan martabat bangsa dihadapan dunia. Namun, dengan memudarnya rasa nasionalisme dan patriotisme dapat mengancam dan menghancurkan bangsa Indonesia karena ketahanan nasional akan menjadi lemah dan dengan mudah dipengaruhi oleh bangsa luar. Bangsa Indonesia sejak dulu sampai sekarang masih dijajah. Seiring berjalannya waktu rasa nasionalisme dan patriotisme generasi muda memudar, salah satu contohnya terjadi tawuran antar pelajar. Dahulu bangsa kita dijajah secara fisik tetapi sekarang bangsa kita dijajah secara ideologi dan mental.

Salah satu cara menanamkan ideologi pancasila untuk mencegah memudarnya nasionalisme yaitu melalui lagu kebangsaa. Musik turut berperan penting dalam perkembangan psikologi dan kehidupan manusia. Musik selalu menyertai dalam kehidupan sehari-sehari, jadi dengan mendengarkan lagu 
kebangsaan tiap hari diharapkan generasi muda dapat menghayati nilai-nilai yang terkandung dalam lagu tersebut dan dapat mengimplementasikan dalam kehidupan sehari-hari. Dalam mencegah memudarnya rasa nasionalisme peran keluarga juga penting yaitu dengan memberikan pendidikan sejak dini tentang sikap nasionalisme dan patriotisme terhadap bangsa Indonesia, keluarga juga memberikan contoh atau tentang rasa cinta tanah air, selalu mengawasi sikap dan pergaulan anak di lingkungan masyarakat. Selain peran keluarga peran pendidikan juga penting, melalui pendidikan khusus pendidikan kewarganegaraan memberikan pengetahuan tentang sejarah, semangat pejuang mengusir penjajah dan pengetahuan tentang menjadi warga negara yang baik yaitu memiliki jiwa pancasila sebagai pedoman hidup dalam berbangsa dan bernegara demi mewujudkan cita-cita bersama. Selain peran keluarga dan pendidikan berperan penting dalam nasionalisme peran pemerintah juga sangat penting. Pemerintah harus sering melakukan kegiatan yang dapat meningkatkan rasa nasionalisme bangsa Indonesia.

\section{DAFTAR PUSTAKA}

Alwisol. (2009). Psikologi Kepribadian. Malang: UMM Press.

Budiman, Arief. (1996). Teori Negara: Negara, Kekuasaan dan Ideologi. Jakarta: PT. Gramedia.

Bramanti, Bayu. (2014). Pengaruh Lagu Metal Terhadap Perilaku Agresif Remaja di Komunitas Metal Pos Merah Samarinda. eJournal Ilmu Komunikasi diakses tanggal 1 Februari 2016.

Darmodihardjo, Dradji. (1996). Penjabaran Nilai-Nilai Pancasila dalam Sistem Hukum Indonesia. Jakarta: Rajawali.

Dedik, S. (2002). Pengaruh Musik Terhadap Perfomance Fisik. Jurnal Teknik Industri diakses tanggal 1 Februari 2016.

Hans, Kohn. (1984). Nasionalisme, Arti dan Sejarahnya. Jakarta: PT. Pembangunan.

Heryanto. (1996). Nasionalisme. Yogyakarta: Pustaka Pelajar.

Kaelan. (2013). Negara Kebangsaan Pancasila. Yogyakarta: Paradigma.

Kartodirdjo, S. (1993). Pembangunan Bangsa, Nasionalisme, Kesadaran dan Kebudayaan Nasional. Yogyakarta: Adytia Media.

Kuntowijoyo. (2001). Radikalisasi Pancasila. Yogyakarta: Makalah untuk diskusi di PPSK.

Lorens, Bagus. (2000). Kamus Filsafat. Jakarta: Gramedia Pustaka Utama.

Notonagoro. (1975). Pancasila Secara Ilmiah Populer. Jakarta: Pantjuran Tujuh. 
Omar, Khalifa. (2008). Pengaruh Mendengarkan Lagu terhadap Kepribadian. Jurnal Ilmiah diakses tanggal 1 Februari 2016.

Puspowardoyo, Suryanto. (1994). Pendidikan Wawasan Kebangsaan. Jakarta: PT. Gramedia Widia Sarana.

Sastrawijaya, S. (1980). Sekitar Pancasila, Proklamasi dan Konstitusi. Bandung: Alumni.

Suparlan, dkk. (2014). Pendikan Kewarganegaraan dalam Konteks Indonesia. Malang: Madani.

Sutarjo, A. Nasionalisme-Demokrasi-Civil Society. Jurnal Ilmiah diakses tanggal 1 Februari 2016.

Suwarno, P.J. (2013). Pancasila Budaya Bangsa Indonesia. Jakarta: Kanisius.

Suteng, Bambang. (2006). Pendidikan Kewarganegaraan untuk SMA kelas X. Jakarta: Erlangga.

Taufik, abdul. (2007). Peranan Nasionalisme. Kompas.

Theresia, R. (2010). Ideologi Pancasila sbagai Dasar Negara. Jurnal ilmiah diakses pada tanggal 1 Februari 2016

Wahid, A. (2006). Pancasila sebagai Ideologi Negara dan dalam Kaitannya dengan Kehidupan Beragama dan Kepercayaan terhadap Tuhan YME. Jakarta: BP-7 Pusat.

Yudohusodo, S. (1996). Semangat Baru Nasionalisme Indonesia. Jakarta: Yayasan Pembangunan Bangsa. 